\title{
TEATRO Y RELIGIÓN EN LA ESPAÑA DE FELIPE II: EL CÓDICE DE AUTOS VIEJOS
}

\author{
Miguel Ángel Pérez Priego
}

UNED

\section{Problemas de AUTORÍA, FECHA y LUGAR DE REPRESENTACIÓN}

Con el título de Códice de autos viejos se viene identificando un volumen manuscrito, conservado desde 1844 en la Biblioteca Nacional de Madrid, que contiene noventa y seis piezas dramáticas - todas de asunto religioso, a excepción del breve Entremés de las esteras-, y que constituye, por tanto, una de las más ricas colecciones de nuestro antiguo teatro sacro '. El manuscrito original está copiado a una sola mano, en letra

' Es el ms. 14711 de la B. N. Portada, en letra moderna: Colección / de / Autos sacramentales, Loas y Farsas / del / siglo XVI (anteriores a Lope de Vega); debajo, a lápiz: «Cbdice de autos viejos $\$ .439$ fols., $290 \times 200 \mathrm{~mm}$. Texto a dos columnas, cada una de 32 a 36 versos. Letra cuidada de la segunda mitad del siglo XVI, originariamente de una sola mano, excepto algún breve añadido. Faltan los ocho primeros folios. Numeración romana de la época en ángulo superior derecho de cada fol., que comienza en el $j x$ y termina en el ccccluvj, con frecuentes saltos y errores; a partir del fol. cliij hay también numeración arábiga moderna a lápiz. Encuadernación en pasta moderna. Tejuelo: AUTOS /SACRAMENT

Procedente de los herederos de don Antonio Porcel, fue adquirido el 18 de julio de 1844 para la B. N. de Madrid por su entonces director don Eugenio de Tapia, por el precio de 960 reales (vid. El Museo Literario, 1844, I, pp. 40-53, II, 100-120, y III, 186-92, donde Tapia describe por primera vez el códice y edita dos de sus piezas). Pocos años después y debido al mal estado de algunas hojas, traspasadas por la tinta más espesa empleada en los encabezamientos y títulos de las piezas dramáticas, fueron restaurados, aunque de muy deficiente manera, 73 fols. (tres de ellos en su integridad). También entonces hubo de efectuarse la encuadernación y componerse la portada y el indice. Antes de perpetrarse esa desafortunada restauración, se hizo una copia completa del códice (ms. 14615) que en esos lugares restaurados refleja, por tanto, lecciones superiores y originarias. 
de la segunda mitad del siglo XVI, y, por desgracia, aparece falto de los ocho primeros folios de texto. Esta irreparable laguna tal vez nos haya dejado sin una respuesta fácil y cierta a los interrogantes fundamentales que plantea la obra acerca de su fecha de composición, su autoría o sobre el carácter mismo de la compilación. Problemas estos para los que ciertamente no tenemos hoy una solución definitiva, pero que son, por ello, los que justifican una investigación detenida e incluso los riesgos de algunas hipótesis.

En cuanto a la cronología, son muy escasos los datos que proporciona el códice. El único preciso es el que aparece en el fol. $280 \mathrm{v}$, donde, a continuación del Auto de la Resurrección de Cristo y en letra diferente a la del texto, figura una autorización, en nombre del vicario general, en Madrid, para que el auto pudiera ser representado la mañana del domingo de Resurrección del año 1578:

«(...) Por la presente, doy licençia para que el auto de la rresurreçión arriba contenido, que está escrito en las siete hojas de atrás, que por mi mandado está visto y examinado, se pueda rrepresentar y rrepresente la mañana de la rresurreçión, con tanto que para la rrepresentaçión dél no se ynpida el serviçio dibino, sin que por ello se yncurra en pena alguna. Ffecho en Madrid, a veynte y ocho de março de mill e quinientos y setenta y ocho años. Por mandado del S. vicario general: Adriano Caldivar.»

Esta licencia de representación, que está hecha sobre la colección ya constituida - pues de lo contrario no se justificarían expresiones como «el auto arriba contenido» o «que está escrito en las siete hojas de atrás», que son las que realmente ocupa el auto en el manuscrito-, viene a indicarnos que la práctica totalidad del códice, tal como hoy lo conocemos, estaba ya compuesto en esa fecha de 1578. Si además tenemos en cuenta que todo él está copiado en letra igual de una misma mano, hay que pensar que hubo de realizarse de modo continuado y en un no muy largo período de tiempo: esto es, no después de marzo de 1578 y probablemente tampoco mucho antes de esa fecha.

Respecto de la cronología particular de las piezas contenidas en la colección, es también poco lo que éstas nos revelan. Léo Rouanet, basándose en la citada autorización de 1578 y en algunos razonamientos personales - hace notar que dos «coloquios» son refundición a lo divino del Coloquio de Fenisa, de 1540, y asegura que el Auto de Naval y Abigail es el que represento en Sevilla Lope de Rueda en 1559-, se decidió, sin mayor abundancia y rigor en los argumentos, a fijar la cronología de las obras entre 1550 y 1575 , aunque cautelosamente no dejaba de advertir que algunas podían tener un origen más antiguo ${ }^{2}$.

2 Léo Rouanet, introducción a su ed. completa del códice, Colección de Autos, Farsas y Coloquios del siglo XVI, Mâcon, 1901, 4 vols, I, pp. XII-XIII. 
Con todo, no es mucho más lo que puede añadirse a estos supuestos de Rouanet, cuya provisionalidad era ya denunciada por Wardropper ${ }^{3}$. Las piezas del códice son muy parcas en referencias cronológicas internas, ya que suelen girar sobre temas y argumentos atemporales (la historia sagrada y los dogmas de la religión). Sólo alguna «farsa sacramental», de construcción alegórica con referente en la propia realidad contemporánea, puede ofrecer alguna mínima y apreciable alusión histórica. Por otra parte, los datos externos escasean también en este tipo de teatro religioso, dada su condición de fenómeno colectivo, tradicional y casi folklórico. Atendiendo, no obstante, a todas esas indicaciones, podrían añadirse todavía algunas precisiones a las fechas propuestas por Rouanet. Así, hay que señalar que tienen que ser anteriores a 1570 la Farsa del sacramento de la fuente de Sant Juan y la Farsa del sacramento llamada premática del pan, puesto que en esa fecha ya las había refundido Juan Timoneda en su Auto de la fuente sacramental y en el Auto de la fe, respectivamente ${ }^{4}$. Asimismo hay que dar por seguro que el Auto del martirio de Sant Justo y Pastor es el mismo que, conforme estudió Manuel Cañete ${ }^{5}$, compuso Alonso de Torres en 1568 con motivo del traslado de las reliquias de aquellos santos desde Huesca a Alcalá de Henares. La Farsa sacramental de las Bodas de España, como ya hizo notar González Pedroso ${ }^{6}$, hubo de escribirse en 1570, puesto que viene a reflejar la ocasión del casamiento de Felipe II con Ana de Austria en ese año. La Farsa sacramental del Amor divino, aunque no se ha reparado en ello, tiene que ser posterior a 1561 , pues en sus versos se alude ya a Madrid como corte ( Vais trillando un camino/ y va muy ciego el carril: / ¿Dónde vais?' 'Para Madril' / ‘A qué vas, me di, mezquino?' / 'Al rey, que me dé cien mill'», vv. 300-304). La Farsa sacramental de la moneda, en fin, puede reflejar una de tantas disposiciones de la época sobre acuñación de moneda, pero si advertimos que uno de sus personajes es el Concilio, con clara referencia a Trento, es muy probable que la pragmática aludida no sea otra que la emitida por el Consejo Real en la fecha próxima de 1566.

Teniendo, pues, en cuenta todos estos datos, podemos afirmar lo siguiente: que el Códice de autos viejos, como tal colección, hubo de formarse entre 1570 y 1578 , quizá no mucho antes de esta última fecha;

${ }^{3}$ Bruce W. Wardropper, Introducción al ceatro religioso del Siglo de Oro, Salamanca, 1967, pp. 211-12.

Cf. E. González Pedroso, Autos sacramentales desde sus origenes hasta fines del siglo XVII, Madrid, B. A. E., LVIII, 1865, pp. 76 y 95; L. Rouanet, ob. cit., IV, pp. 123 y 328; Obras de Juan de Timoneda, ed. E. Juliá Martínez, Madrid, Sociedad de Bibliófilos Españoles, 1948, II, pp. XXVII-XXX.

5 Manuel Cañete, Teatro español del siglo XVI. Estudios histórico-literarios, Madrid, 1885, pp. 297-317.

6 E. González Pedroso, ob. cit., p. 74. 
que ninguna de las obras contenidas en él debe ser posterior a 1578 y, por los datos examinados que revelan varias de ellas, es presumible que la mayoría se compusieran, en la forma que las conocemos, entre 1559 y 1578 (con lo que creemos debe adelantarse algo la cronología de Rouanet). Ello no quiere decir, sin embargo, que estas obras no puedan ser reelaboraciones, refundiciones o incluso copias de otras más antiguas. Por el contrario, como tendremos ocasión de ir comprobando, estamos persuadidos de que buen número de ellas no son sino variaciones de piezas anteriores sobre el mismo argumento.

Por lo que respecta a la autoría de las obras, todas ellas figuran en el códice sin nombre de autor y sólo una, el Auto de Caín y Abel, lleva, al margen del texto y en letra diferente, la firma del «Maestro Ferruz» ${ }^{7}$. Fuera de ese caso, no existe en ninguna otra la menor referencia expresa a sus autores. No obstante, por los argumentos dramáticos tratados o por sus especiales características literarias, hay algunas que permiten ciertas conjeturas acerca de esa identidad. Tal sucede con el ya citado Auto de Sant Justo y Pastor, que sería obra del maestro Alonso de Torres, célebre latinista y catedrático de retórica en Alcalá. Por ciertos rasgos de composición -está escrito en prosa y contiene escenas de criados con abundancia de elementos cómicos y risibles-, puede pensarse que el Auto de Naval y Abigail sea obra de Lope de Rueda, quizá adaptado de una versión anterior ${ }^{8} \mathrm{y}$, según sabemos, representado por él mismo en Sevilla en $1559^{9}$. También es probable que el Auto de la prevaricación de nuestro padre Adán sea obra del dramaturgo extemeño Micael de Carvajal, quien, según afirma en el prólogo de su Tragedia Josephina, compuso diverso número de autos religiosos que anduvieron lejos de su paternidad en la época: uno de ellos pudo ser este de nuestro códice que, efectivamente, refleja conceptos, fórmulas expresivas y recursos dramáticos (prólogo, coros) que ya se contenían en la Josephina ${ }^{10}$. El Auto del rey Nabucodonosor quando se

7 Sobre Jaime Ferruz y su obra, véase M. Cañete, ob. cit., pp. 251-94, y Henri Merimée, L'Art dramatique d Valencia depuis les origines jusqu'au commencement du XvIr siecle, Toulouse, 1913, pp. 227-42.

${ }^{8}$ En Medina de Rioseco, en 1554, consta que el municipio concertó con Cristóbal Gil y Francisco de Pumar tres autos para las fiestas del Corpus de ese año: el segundo de esos autos «será quando el rey David estando en el campo, le faltaron los bastimentos y les envió a pedir a Nabal su criado y le respondió que no se les queria dar, y viendo el rey David la respuesta, va contra él para destruirle, y yendo en esta ostinación topó con Aviginal su muger que llevava los bastimentos al real del rey David, y se puso a sus pies y alcançó perdón a su marido, y con esto se acabó. Es de la sagrada escriptura» (cf. E. García Chico, «Documentos referentes al teatro en los siglo XVI y XVII», Castilla, I, 194041, p. 339).

José Sánchez-Arjona, Noticias referentes a los Anales del teatro en Sevilla desde Lope de Rueda hasta fines del siglo XVII, Sevilla, 1898, pp. 10-18.

10 Micael de Carvajal, Tragedia llamada Josephina, ed. de Joseph E. Gillet, Princeton, 1932, pp. XVIII-XIX. 
hizo adorar, como tuvimos ocasión de exponer en otro lugar, es seguramente la «tragedia» que sobre el mismo personaje compuso el padre Juan Álvarez, rector del colegio de jesuitas de Plasencia, para las fiestas del Corpus de $1563^{11}$. Más dudoso resulta, en cambio, que el Auto del sacrificio de Abraham y el Auto de la degollación de Sant Juan Bautista, como alguna vez se ha sugerido, sean obra de Vasco Díaz Tanco de Fregenal, pues de su teatro religioso no tenemos más noticia que la relación de títulos que él mismo ofrece en el prólogo de su Jardín del alma cristiana (1552), de los cuales no se ha conservado texto alguno ${ }^{12}$. La Farsa de la Esposa de los Cantares, por último, es prácticamente idéntica al Auto de la Esposa en los Cantares, recogido en el Cancionero general de la Doctrina Cristiana (Alcalá de Henares, 1579) de Juan López de Úbeda. Pero, como revela el cotejo de ambos textos, no se trata de una adaptación directa de dicho auto, sino de la reelaboración de un texto original más antiguo y común a las dos piezas, y que López de Úbeda, muy dado también a rehacer material ajeno, hubo de incorporar por su cuenta al Cancionero, incluso tal vez ya en la edición perdida anterior a $1579^{13}$.

En cuanto al lugar para el que se compusieron o donde se representaron las obras del Códice, también son todo problemas. La única que ofrece plena seguridad es el citado Auto de la Resurrección, que lleva, como vimos, autorización expresa para ser representado en Madrid. Un marcado localismo madrileño refleja asimismo la Farsa del sacramento de la fuente de gracia, que menciona en sus versos cuatro famosas fuentes de la villa: la «fuente de Leganitos», "Lavapiés», la «fuente del Peral» y la «fuente de la Priora» ${ }^{14}$. La Farsa del Amor divino, como dijimos, habla ya de Madrid como residencia del rey. La Farsa sacramental de la moneda se inspira quizá en la pragmática de 1566 promulgada en la Corte, y la de la Entrada del vino y la de la Pragmática del pan es muy probable que recojan en sus argumentos asuntos de actualidad de organización de la vida ciudadana sobre los que repetidamente insistían las ordenanzas municipales ${ }^{15}$. Vinculado a Alcalá de Henares

1 M. A. Pérez Priego, «Notas sobre el teatro religioso en Plasencia durante el sien Miscelánea Cacereña, Cáceres 1980, pp. 90-91.

12 Examinó su teatro J. E. Gillet, *Apuntes sobre las obras dramáticas de Vasco Díaz RABM, XLIV (1923), pp. 352-56. También tratamos nosotros del autor en nuestro estudio El teatro de Diego Sánchez de Badajoz, Cáceres, 1982, pp. 48-50.

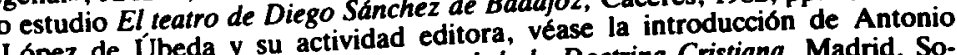

Rodrígure Lopez de Ubeda Cancionero general de la Doctrina Cristiana, Madrid, Sociedad de-Moñino a suspañoles, 1962-64, 2 vols. López de Úbeda era natural de Toledo, pero en Alcalá fundó un Seminario de Niños de la Doctrina Cristiana, en cuyo beneficio escribe y publica el Cancionero.

fuentes de Madrid*, RABAM, VII (1930), pp. 371-88.

等 Cf. Agustín G. de Amezúa, «Las primericorion, Madrid, 1951, III, pp. 78-115; An- 
se muestra, en cambio, el Auto de Sant Justo y Pastor, y también de allí proceda tal vez el texto primitivo de la Farsa de la Esposa de los Cantares.

Para ser representada en Toledo, como sugirió González Pedroso ${ }^{16}$, hubo de componerse la Farsa sacramental de las Bodas de España, que incluye referencias localistas al reloj de la catedral (v. 153) y al «armario de Juanelo» (v. 175) ${ }^{17}$. De Toledo o sus contornos deben de ser también el Auto de la Verdad y la Mentira, que menciona a un Muñoz azotado «en Toledo estotro día» (v. 458), y la Farsa del sacramento de los quatro Evangelistas, que cita el pueblo de San Pedro de la Mata (v. 103). Por lo demás, con la rica tradición teatral toledana, últimamente estudiada por Carmen Torroja y María Rivas ${ }^{18}$, pueden entroncar varias piezas del códice cuyos argumentos coincidirían con los de algunas representaciones que se venían haciendo en Toledo desde el siglo XV, aunque al carecer de los textos de éstas no pueden ser seguras las conclusiones. Tales argumentos coincidentes serían: «El pecado de Adán», «La degollación de San Juan», "La Resurrección», "La quinta angustia» (sobre el descendimiento de la Cruz), «El sacrificio de Abraham», «La reina Elena» (sobre la invención de la Cruz), «La Asunción», "La entrada en Jerusalén», «El rey Nabuc», «Caín y Abel» y «San Jorge». En todo caso, esas coincidencias se vienen a producir en algo más de un diez por ciento del total de los argumentos que tratan las noventa y seis piezas del códice. En consecuencia, diez o doce de éstas pueden provenir de la tradición toledana, pero nada hace suponer que tal ocurra con las ochenta y tantas restantes.

Por último, otro buen número de obras de nuestro repertorio habría que relacionarlo con Sevilla y la intensa actividad dramática que allí se desarrolla en la época. Con los títulos de las que entonces se representan, y que conocemos gracias a los anales diligentemente confeccionados por Sánchez Arjona ${ }^{19}$, vienen a coincidir, en efecto, bastantes de los de nuestra colección. Entre ellos, los menos discutibles serían: «El hijo pródigo», «Navalcarmelo» (representados ambos por Lope de Rueda en 1559), "San Jorge» (1559), «Abraham», «Los cinco sentidos» (los dos de 1560), "El rey Nabucodonosor y el horno», «Tobías», «La

tonio de León Pinelo, Anales de Madrid, ed. de P. Fernández Martín, Madrid, C.S.I.C., 1970.

${ }^{16}$ Ob. cit., pp. 73 y 74.

17 Se trata de Juanelo Turriano, famoso inventor italiano establecido a mediados del siglo XVI en Toledo a instancias de Carlos V. De él se conserva en la B. N. de Madrid una curiosa obra en cinco vols. titulada Los veintiún libros de los ingenios y máquinas, dedicada a Felipe II (mss. 3372-3376).

${ }^{18}$ Carmen Torroja Menéndez y María Rivas Palá, Teatro en Toledo en el siglo xv. "Auto de la Pasión. de Alonso del Campo, Madrid, Real Academia Española, 1977.

19 J. Sánchez-Arjona, Noticias..., cit. 
circuncisión del Señor» (los tres de 1561), «La Asunción de Nuestra Señora» (1564), "San Antonio y San Pablo», «Dina hija de Jacob», «El desafío de Lucifer con el hombre» (los tres en 1570), «La demanda que pone el demonio al género humano», «Los desposorios de Joseph», «Los desposorios de Cristo con la naturaleza humana» (los tres en 1575), «La huida a Egipto», «El rescate del alma», «El viaje del hombre», «San Justo y Pastor» (los cuatro en 1576), «El juicio» y «Joveniano" (ambos en 1577). Todo ello supondria alrededor de un veinte por ciento del contenido del códice, aunque también habría que advertir aquí que, al no contar con el texto de estas representaciones sevillanas, tampoco puede asegurarse rotundamente la identidad.

En resumen, y como conclusión de todo lo dicho, lo más seguro es que el Códice refleje la actividad dramática no de un único lugar sino de diversas áreas geográficas. Entre ellas, tenemos por más reveladora - confirmada además con mayor evidencia documental- la relación que guarda con la capital del reino. El Códice de autos viejos, en su conjunto, nos parece que responde bien al ambiente social y religioso que vive Madrid en los años inmediatos a 1561 cuando Felipe II traslada a ella la capitalidad del reino. A ese ambiente nuevo y a la necesidad que se crearía de competir y superar a las demás ciudades en la celebración de las fiestas religiosas, particularmente la del Corpus Christi ${ }^{20}$, puede muy bien deber su existencia esta extraordinaria y sorprendente recopilación de materia dramática.

De todos modos, como queda dicho, muchas de esas piezas se relacionan también con otros diversos lugares, donde igualmente hubieron de representarse antes e incluso después de constituida la colección. Tal ubicuidad y diversidad geográfica, a nuestra manera de ver, excluye la posibilidad de que la colección suponga - como quizá pudiera pensarse- la producción o el fondo teatral de una sola ciudad o iglesia particulares y, en cambio, nos parece que sólo podría explicarse si pensamos en la movilidad de una compañía teatral que trajera y llevara las obras de un lugar a otro. En consecuencia, creemos que el Códice de autos viejos hay que relacionarlo con la ya por entonces vigorosa actividad de los comediantes profesionales, y no cabría sino entenderlo como un repertorio dramático a disposición de una compañía teatral ${ }^{21}$ y tal

20 Por los Libros de Acuerdos del Archivo de la Villa sabemos que en 1561 se pidio que se gastaran treinta mil maravedís en autos y danzas «puesto que ha de venir a esta Villa Su Magestadw, y en el acta de la sesión para organizar los festejos del Corpus del año siguiente se hace constar: «e porque el ańo pasado no se hizo hesta ninguna ni se gastaron los dichos treinta mil maravedís (...) aora, por estar aquel Fernández Álvarez, *El tad conviene que se haga muy bien la dicha fiesta* (apud Maciedad y Corona (Ensayos históricos sobre el siMadrid de Felipe II\%, en Econom
glo XVI), Madrid, 1963, p. 257).

21 En realidad, la crítica que se ha venido ocupando del Códice pocas veces se ha 
vez allegado por algún destacado «autor» de compañías. Pero esta explicación requiere algunas consideraciones previas.

\section{EL TEATRO RELIGIOSO Y LOS COMEDIANTES}

El fenómeno seguramente más importante que se produce en la evolución del teatro religioso en la segunda mitad del siglo XVI es el del paso de las representaciones a manos de los actores profesionales, a los autores de compañías. Si hasta entonces, en la generalidad de los pueblos y ciudades, eran los cabildos, las cofradías y gremios, los propios clérigos y aficionados piadosos los encargados de mantener las fiestas y ejecutar las representaciones, ahora puede observase cómo, sobre todo en las grandes ciudades (Sevilla, Toledo, Madrid, Valladolid), y particularmente con ocasión de las fiestas del Corpus Christi, comienzan a aparecer las compañías de actores que, contratadas unas veces por el cabildo y otras por el municipio, vienen a hacerse cargo de las representaciones dramáticas.

En Valladolid, ya en 1551 , el ayuntamiento contrata al representante Alonso de Madrid para servir en las fiestas del Corpus y, en 1552, hace lo propio con Lope de Rueda, a quien asigna además un salario anual de cuatro mil maravedís para que fije su residencia en la villa como maestro perpetuo de esas fiestas ${ }^{22}$. En Sevilla, en 1554, los gremios y hermandades renuncian a seguir siendo mantenedores de la fiesta del Corpus («que si la ciudad quiere hacer juegos y danzas lo pague de los propios y rentas que tiene y que no moleste a los vecinos») ${ }^{23}$, y serán, en efecto, las autoridades municipales quienes, a partir de ahora, principalmente costeen las representaciones del Corpus, las cuales serán convocadas mediante concurso y elegidas de acuerdo con el dictamen de un provisor eclesiástico, estableciéndose además un premio en metálico para las mejores ${ }^{24}$. En Madrid, de

preguntado por la condición de esta enigmática recopilación de textos. Únicamente N. D. Shergold creemos que ha planteado de modo explícito el problema: «No one knows the origins of this collection, or the reasons why it was made, so it is impossible to say whether it constituted a body of religious plays owned by a church, or by a company of actors, or whether it was collected together for some other purpose, perhaps for publicationn (A History of the Spanish Stage from medieval times until the end of the seventeenth century, Oxford, 1967, p. 89), aunque en otro lugar de su estudio, p. 111, sugiere que pueda tratarse de un repertorio de piezas sacras acumulado de año en año por los actores. (Vid. más abajo nota 31).

${ }_{22}$ Narciso Alonso Cortés, «El teatro en Valladolid», BRAE, IV (1917), pp. 605-609.

23 J. Sánchez-Arjona, El teatro en Sevilla en los siglo XVI y XVII, Madrid, 1887, p. 37.

24 Ibid., pp. 41-45; vid. también Vicente Lleó Cañal, Arte y espectáculo: la fiesta del Corpus Christi en Sevilla en los siglos XVI y XVII, Sevilla, 1975, p. 32. 
donde no poseemos documentación definitiva hasta fechas algo tardías, el más antiguo documento conservado, de 1574, nos informa que el «autor» de comedias Jerónimo Velázquez se obligo a hacer para la fiesta del Corpus de ese año «tres autos, el uno de la Pesca de San Pedro, y el otro de la Vendimia celestial y el otro del Rey Baltasar quando en sus convites profanó los vasos del templo»; Velázquez además pondría «todos los personajes y aderezos de vestidos y todas las demás cosas que para la dicha representación fueren necesarios», en tanto que la villa «le ha de dar tres carros aderezados con todos los artificios que fueren necesarios para las representaciones (...) y pagar ciento y treinta ducados» 25 .

En Toledo, donde las representaciones dependieron siempre del cabildo catedralicio, en 1561 se encargó a Lope de Rueda la representación de los autos del Corpus, por lo que se le abonaron ciento cuarenta ducados. En 1579 es el italiano Curcio y sus compañeros quienes representan para el Corpus, en tanto que en 1580 son las compañias de Alonso Rodríguez y Melchor de Herrera y, en 1581, la de Pedro de Saldaña ${ }^{26}$. Las representaciones toledanas, por lo que sabemos, eran organizadas por dos canónigos designados como mayordomos, los cuales concertaban las condiciones con los directores de compañías. El dia del Corpus solían representarse cuatro autos, con sus entremeses, y una farsa sacramental (el día de la Octava eran sólo dos autos con tres entremeses), tal como indica un documento de 1585, por el que el cabildo encarga a Diego de la Ostia y a Alonso Gómez:

«cinco autos: uno de la Entrada de nuestro señor en Jerusalén, y otro del capitán Josué quando ahorca al rey Amorreo, y otro quando Cristo entrego las llaves a San Pedro, otro quando bajo Moysén del monte con las tablas, y la farsa sacramental que ha de ser sobre el Socorro de los pobres de la Mancha, y en cada un auto destos un entremés» ${ }^{27}$.

Las mismas circunstancias vienen confirmadas por una carta de obliga-

${ }^{25}$ Cristóbal Pérez Pastor, Nuevos dalos acerca del histrionismo español en los siglos XVI y XVII, Madrid, 1901, pp. 333-34. Véase también N. D. Shergold y J. E. Varey, *Documentos sobre los autos sacramentales en Madrid hasta 1636*, RBAM, XXIV (1955), pp. 203-313; Id. id., «Autos sacramentales en Madrid hasta 1636», EE, IV (1959), p. 54; J. E. Varey, «La mise en scène de l'auto sacramental à Madrid au XVI et $\mathrm{XVII}^{e}$ siécles», en J. Jacquot (ed.), Le lieu theâtral d la Renaissance, París, 1964, p. 215; Mercedes Agullo y Cobo, $\kappa$ Documentos sobre las fiestas del Corpus en Madrid y sus pueblos*, Seg, XV-XVI (1972), pp. 51-63.

${ }^{26}$ Francisco Asenjo Barbieri, «Migajas de la historia», en Toledo, publicación quincenal e ilustrada, I, 1889.

${ }^{27}$ Francisco de B. San Román, Lope de Vega, los cómicos toledanos y el poeta sastre, Madrid, 1935, pp. LV-LVIII. 
ción de 1592, en la que los autores Francisco y Rodrigo Osorio se comprometen a hacer los autos del Corpus, que

«han de ser cinco autos de la forma y manera y de las historias y representaciones que los dichos mayordomos nos pidieren, los quales dichos autos y farsa sacramental y cinco entremeses en cada carro haremos en la dicha santa iglesia a las horas que nos fuere ordenado, y en las demás partes que nos fuere ordenado y mandadon.

En cuanto a las exigencias que imponía el cabildo a los autores, es muy ilustrativo el documento que en 1593, para el Corpus de 1594, firman Alonso de Cisneros, Gaspar de Porres y Miguel Ramírez, por el que

use obligaron de representar cinco autos en el dicho día de Corpus Christi, los dos por la mañana y tres por la tarde, los quales dichos cinco autos han de ser los que señalaren los señores mayordomos de los dichos señores deán y cabildo, y para que los dichos señores mayordomos puedan escoger y señalar los dichos cinco autos que quieren se hagan, sean obligados y se obligaron a entregar a los dichos señores mayordomos cantidad de autos di. ferentes: 29.

En consecuencia, parece que era práctica habitual del cabildo toledano o bien encargar determinados autos a los representantes, como indican los documentos de 1582 y $1592^{30}$, o bien elegir de entre los que se les habían presentado con antelación y en cantidad suficiente, según se desprende del documento de $1593^{31}$.

Muy diversos motivos hubieron de provocar, sin duda, esta circunstancia del paso de las representaciones religiosas a manos de los actores profesionales. De entre ellas, no sería la menos decisiva el abierto proceso de reforma de las representaciones sacras que desde tiempo atrás venía promoviendo la propia Iglesia ${ }^{32}$, y que culmina en las disposi-

28 Ibid., pp. 11-12.

29 Ibid., p. 17.

30 También uno de los autos recogidos en el llamado Códice de 1590, el del Testamento de Cristo, lleva al frente la siguiente ilustrativa anotación: $\times$ Hecho a deboçión de la sancta yglesia de Toledo que lo mando conponer en el año de 1582* (cf. Vera Helen Buck, Four *Autos Sacramentales* of 1590, University of Iowa Studies, 1937, p. 80).

${ }^{31}$ N. D. Shergold llamó ya la atención sobre este interesante documento, el cual, según sus palabras, «suggest that for their part, the actors accumulated from year to year a repertoire of religious plays from which the organizers of the Corpus Christi festivity could choose; and it may be that this provides the explanation of the Rouanet collection -the Códice de autos viejos- could be just such a repertoire» (ob. cit., p. 111).

32 Vid. Marcel Bataillon, «Ensayo de explicación del auto sacramental», en Varia lección de clasicos españoles, Madrid, 1964, pp. 189-95. 
ciones de los concilios provinciales de 1565 , que recogen los dictámenes de Trento. Uno de los puntos en que insistían más aquellas disposiciones era, en efecto, el de la prohibición terminante de que los clérigos siguieran actuando en representaciones dramáticas. En tal sentido, dictamina el Concilio Provincial de Toledo:

*Y para que nada se haga que no convenga al orden eclesiástico, prohibe el santo concilio que los ordenados de mayores o beneficiados, en ningún lugar y tiempo se dejen ver vestidos de máscara, ni representen en espectáculos ni juegos, castigando a los contraventores con la suspensión del oficio y beneficio, y con una multa grave a arbitrio del ordinarion ${ }^{33}$.

\section{Y el Concilio Compostelano, aún con mayor rigor y dureza:}

"Los ordenados de mayores conviene que no se presten a gozar de los delites vanos y espectáculos voluptuosos. La transgresión de esto ha sido motivo de que justamente los sagrados cánones hayan reprimido la intemperancia de algunos presbíteros, diáconos y subdiáconos, los cuales no solo introducen en las iglesias diversiones teatrales, sino que en algunas festividades se prestan a ser actores de su locura. Por lo tanto, a ninguno de los antedichos sea lícito hacer de payaso, juglar o histrión, bien se represente un asunto profano, bien espiritual; y el contraventor será castigado por el obispo con las merecidas penas aplicadas a las iglesias, de modo que este decreto se observe piadosa $e$ inviolablementex ${ }^{34}$.

En cambio, y frente a ese rigor con que eran vedadas las representaciones a los clérigos, la autoridad eclesiástica comenzó a ver con no malos ojos el que esas mismas representaciones pasaran a manos profesionales, ya que así, seguramente, ganaban en autenticidad y rigor, y mejoraba, sin elementos perturbadores y risibles, su condición edificante y carácter devoto ${ }^{35}$. Los actores profesionales, por su parte, no

33 Apud Juan Tejada y Ramiro, Colección de cánones y de todos los concilios de la Iglesia Española, t. V, Madrid, 1855, p. 238.

34 Ibid., p. 331. Esta actitud de la jerarquía eclesiástica contrasta vivamente con la permisividad que sobre las representaciones a cargo de los clérigos estaba vigente desde la época de las Partidas.

${ }^{35}$ En este sentido, son elocuentes las palabras del franciscano fray Francisco de Alcocer en su Tratado del juego (Salamanca, 1559): *Las representaciones de farsas y invenciones es otra manera de juego, las cuales cuando son de historia de la Sagrada Escritura o de otras cosas devotas y se hacen por personas que las representan con aquella graciosidad que cosas semejantes requieren, es regocijo honesto y bueno y provocativo de devoción. Y siempre se debía procurar que las personas que las representan entendiesen tam bién lo que hacen y representan y estuviesen tan diestros en ificase y provocase a devoción bien lo que dicen, que el pueblo que está presente se edificase y provocase a devoción. 
tardarían en demostrar su superioridad sobre los aficionados y en seguida pasarian a ser elemento imprescindible del espectáculo ${ }^{36}$.

Pero, a nuestro propósito, lo que ahora nos interesa examinar son, más que las causas, las consecuencias de aquel fenómeno. En ese orden de cosas, conviene señalar ante todo que, con la llegada y el acceso de las compañías a la fiesta religiosa, aumentará de modo considerable respecto a épocas anteriores la documentación teatral que poseemos, en virtud de los numerosos contratos y cartas de obligación que ahora se expiden ${ }^{37}$ (aunque también hay que decir que este aumento no se producirá en modo suficiente $y$, por ejemplo, no se nos trasmiten apenas títulos de las obras representadas, ya que los contratos se firman meses ántes de la fiesta y era más tarde, en las vísperas, cuando se señalaban o escogían las representaciones). Por otro lado, el teatro se va a convertir en un espectáculo multitudinario, con gran aparato, incluso cierto derroche, y gran concurso de gentes. En Sevilla, por ejemplo, sabemos que las fiestas del Sacramento se celebraban «con grandíssimo excesso de primores y regustos», aventajando a todos los lugares de España y gastando en ellas «cinco mill y quinientos escudos» («en solas representaciones y danças gastan este día cerca de los tres mill») ${ }^{38}$. Se produce, así, por todas partes, una intensísima actividad teatral, que además se verá estimulada por la competencia y rivalidad entre unas ciudades y otras, así como entre las propias compañías.

Como consecuencia de todo ello, se va a necesitar una extraordinaria abundancia de materia dramática y representable. En Toledo, como quedó dicho, son cuatro autos y una farsa los que de ordinario se representan cada año en la festividad del Corpus. En Madrid, por lo menos desde 1574 , son tres autos ${ }^{39}$. En Sevilla, según el testimonio de Messía de la Cerda, son también cuatro los autos habitualmente representados ${ }^{40}$. Los autores de compañías se verán obligados, pues, a disponer de un nutrido repertorio de piezas representables, sobre el cual,

(apud Emilio Cotarelo y Mori, Bibliografia de las controversias sobre la licitud del teatro en España, Madrid, 1904, pp. 54-55).

36 Vid. B. W. Wardropper, ob. cit., pp. 80-81.

${ }^{37}$ Vid. Jean-Louis Flecniakoska, La formation de l'«auto* religieux en Espagne avant Calderón (1550-1635), Montpellier, 1961, p. 91.

${ }^{38}$ Reyes Messía de la Cerda, Discursos festivos. En que se pone la descripçión del ornato e invenciones que en la fiesta del Sacramento la parrochia collegial y vezinos de Sant Salvador hizieron, año de 1594 (Biblioteca Nacional de Madrid, ms. 598, fol. 1).

${ }^{39}$ Tal es el número que se mantiene en los contratos que en años sucesivos firmarán Velázquez, Alonso de Cisneros, Gaspar de Porres, Nicolás de los Ríos, etc. En 1592, Porres y Rodrigo de Saavedra firmarán ya cuatro autos, número que se repetirá en los años sigujentes del sigio.

${ }^{40} \mathrm{R}$. Messía de la Cerda, ob. cit., fol. 7r: «las representaciones son quatro, divididas en ocho medios carros de grandíssima máchina y longitud; las danças ocho, todas de mucho reguzijo, y éstas con las representaciones duran todo el dían. 
como indican los documentos de Toledo o Madrid citados más arriba, los mayordomos y comisarios «eligen» o «señalan» unos títulos determinados para la correspondiente fiesta del Corpus.

Ahora bien, lo más significativo es que esas obras de que pasan a disponer los representantes son en su mayoría anónimas y no impresas. Sólo en fechas más avanzadas, prácticamente ya en el siglo XVII, esos textos para representar serán obra de dramaturgos profesionales y de éxito, a quienes los encargan los propios directores de compañías en virtud de los estrechos vínculos que entre unos $y$ otros se han ido creando en el espectáculo profano de los corrales ${ }^{41}$. Pero antes de que se llegara a esa situación, las compañías - sin duda, siempre escrupulosas con la corrección y licitud de los textos que iban a representar, aparte el control y vigilancia que sobre ellas ejercian los cabildos y comisarios- hubieron de abastecerse y atenerse a obras de naturaleza muy heterogénea. Unas serían las que ya venían siendo representadas anteriormente y contaban con la legitimación de la tradición y la costumbre. Otras serían las que pusieran a su disposición los propios cabildos o municipios que, a su vez, las habrían encargado a clérigos, maestros de retórica o poetas espirituales, quienes también muchas veces se limitarían a actualizar y reelaborar textos más antiguos. Otras, en fin, como documentaría el caso de Lope de Rueda más arriba citado, pudieron incluso rehacerlas los propios autores de compañías. De todos modos, se trata siempre de obras anónimas, en las que no ha habido una voluntad individual de perpetuar el nombre de autor, bien debido al carácter tradicional y colectivo con que se venía concibiendo este teatro religioso, bien debido a la escasa estimación literaria que los propios autores, en su mayoría clérigos, concederían a esas obrecillas. A base de este material de acarreo que, por las mismas razones que circuló anónimo, tampoco gozó casi nunca del favor de las prensas y se difundió habitualmente en copias manuscritas ${ }^{42}$, los autores de compañías elaborarían sus repertorios dramáticos. Repertorios que normalmente no hubieron de ser muy extensos y variados, pero que en el caso de algunas compañías importantes y de larga vida, o en circunstancias especiales, pudieron alcanzar una sorprendente amplitud.

41 Lo que no impide, sin embargo, que todavía entonces se eche mano ocasionalmente de los «autos viejos» para las representaciones del Corpus, bien porque las compañías tratan de presentarlos como «nuevos» sólo con cambiarles el título, bien porque no les hayan llegado a tiempo los encargados a un autor famoso (cf. Jean-Louis Flecniakoska, ob. cit., pp. 94-100, quien refiere allí varios casos ilustrativos).

42 Este hecho es. sin duda, el que indujo al conde de Schack, en su célebre Historia de la literatura y del arte dramático en España (trad. esp. por E. de Mier, Madrid, 1885, I, p. 384), a afirmar que «no existe drama alguno religioso que corresponda al período comprendido entre 1561 y los últimos diez años del siglon, ausencia que él achacaba supuestamente a las prohibiciones de los concilios provinciales. 
Uno de esos repertorios excepcionales hubo de ser precisamente nuestro Códice de autos viejos, el cual debería además su mayor importancia histórica al hecho de haber sido prácticamente el único de su género y condición que ha llegado hasta nosotros. Como, en efecto, hace presumir aquella intensísima actividad teatral reseñada, habría mucha más "materia» dramática representable que, sin embargo, no ha sobrevivido. Cuando las piezas del Códice debían estar en plena vigencia, las décadas de 1560 a 1580 , la mayoría de los títulos que sabemos fueron representados entonces corresponden, en cambio, a autos y farsas que no aparecen recogidos en nuestra colección. Tal sucede con los que por esas fechas conocemos de Madrid («La pesca de San Pedro», «La vendimia celestial» y «El rey Baltasar», representados en 1574 por Jeronimo Velázquez) o de Toledo («La entrada en Jerusalén», "Josué y Amorreo", "Christo y San Pedro», "Moysén quando bajó del monte con las tablas» y la farsa sacramental del "Socorro de los pobres», representados todos en 1585 y de los cuales sólo el primero podría corresponderse con el Auto de la entrada de Christo en Jerusalén de nuestro Códice) ${ }^{43}$. Incluso en Sevilla, donde la documentación conservada sí consigna prácticamente todos los títulos de las piezas representadas esos años y donde, como vimos, muchos de ellos coinciden con los del Códice, la mayor parte, sin embargo, tampoco guardan correspondencia con los incluidos en éste ${ }^{44}$.

De esa condición de repertorio de representantes se derivarían, por lo demás, ciertas características materiales del Códice que, de otro modo, creemos no encontrarían una explicación satisfactoria. Como ya dijimos, sólo si pensamos en la actividad trajinante de una compañía de actores se puede justificar que obras de autores y lugares distintos, así como de diversa cronología, estén incluidas en la colección. Debido igualmente a esa heterogeneidad y al afán acumulativo e indiscriminado con que ésta se formaría, se explica también que en ella se repitan obras de idéntico argumento en versiones diferentes (hay, por ejemplo, dos piezas sobre Los desposorios de Isaac, tres sobre la Asunción de Nuestra Señora, tres sobre la Resurrección de Christo, etc.) o incluso haya piezas que reiteren el mismo texto con sólo ligeras variantes amplificativas (el auto y la farsa sacramental sobre La residencia del hombre o los dos autos de La conversión de San Pablo).

${ }^{43}$ Ésos son los únicos títulos de que han dejado constancia los documentos más arriba citados de Madrid y Toledo, donde, como dijimos, es poco frecuente que los contratos consignen el título de las obras que se iban a representar.

Así puede comprobarse en la larga lista de títulos que relaciona J. Sánchez-Arjona en sus Anales citados. 
En un repertorio así no sorprendería tampoco que, junto a las piezas dramáticas, puedan estar incluidas también otro tipo de composiciones poéticas, como las «coplas» $y$ «loas» de diverso asunto que aparecen a continuación de algunos autos en el manuscrito (coplas a San Francisco, San Juan y San Ambrosio, a continuación del Auto de los desposorios de Isaac; coplas a la Vera Cruz tras el Auto de Abraham y el del Hospedamiento que hizo Santa Marta a Christo; una «Loa para cualquier auto», otra «A un prelado 0 otro señor» $\mathbf{y}$ "A un pueblo», todas a continuación de la Farsa del sacramento del Amor divino, folio 42 , etc.). Tales composiciones tendrían en el repertorio una gran funcionalidad de uso y curiosamente vienen a completar allí casi siempre los blancos de los pliegos y folios que dejaba libres la copia de las piezas dramáticas ${ }^{45}$. De modo semejante se han de justificar también las repetidas indicaciones en el interior de los textos acerca de la presencia de un entremés que, sin embargo, nunca se transcribe («Aquí a de aver un entremés...», «Entranse todos, y avrá aquí entremés...», etcétera).

La misma ordenación de las obras en el manuscrito respondería también mejor a aquella condición y circunstancias. Ciertamente no se observa a primera vista un orden muy riguroso en la disposición de las piezas que integran el Códice, en el que vemos mezclados «autos». y «farsas», además de la ya comentada presencia intermitente de «coplas» y «loas» sueltas. No obstante, si bien se advierte, donde esta mezcla se hace más ostensible es precisamente en los comienzos del manuscrito, en sus primeros cincuenta folios aproximadamente, donde se recogen varios autos de asunto bíblico, dos farsas sacramentales y diverso número de coplas y loas. Reparando en ello, quizá no fuera mucho pensar que el Códice haya podido formarse a partir de un pequeño repertorio que aparecería configurado en sus nueve primeras piezas (podrían ser diez o incluso once si tenemos en cuenta que faltan los ochos primeros folios del manuscrito). Ese breve repertorio sería el propio y ordinario de una compañía de actores -de aquellas que, como quedó dicho, se obligaban a representar en el Corpus tres o cuatro autos, más una o dos farsas, que elegían los organizadores de entre todos los que les presentaban- y contendría un pequeño elenco de piezas dramáticas: en este caso, siete autos, dos farsas sacramentales, varias coplas en loor de diversos santos y tres loas que satisfarían todas las necesidades de representación que se plantearan ${ }^{46}$.

45 En alguna ocasión, como sucede en el Aucto de la conversión de la Madalena, la copia deja en blanco una columna del folio, lugar donde debería haber ido alojada la loa que, sin embargo, falta; en la Farsa sacramental llamada desafio del hombre, en cambio, se ha copiado la loa a continuación del texto de la farsa.

46 El contenido de los primeros cincuenta folios del Códice es el siguiente: Auto del 
Sobre ese primer núcleo y teniendo a la vista otros breves repertorios semejantes, pudo crearse luego este magno repertorio de noventa y seis obras, que el compilador tiende ya a clasificar en un orden temático y argumental más estricto, aunque no exento de interferencias e irregularidades. De ese modo, en la disposición definitiva de nuestro repertorio puede observarse una cierta ordenación por series de obras. Habría así un primer bloque de autos, del número 1 al 22 , que tratan por lo general asuntos del Antiguo Testamento (Abraham, Agar, Jacob, Isaac, Sansón, Nabucodonosor, Asuero, David, José, Tobías); a continuación, del 23 al 39, otra serie de autos sobre vidas de santos y leyendas piadosas (Juveniano, San Pablo, San Jorge, San Cristóbal, San Andrés, destrucción de Jerusalén, Asunción de Nuestra Señora, Santa Elena, Santa Bárbara, etc.); del 40 al 50 , un grupo de autos sobre la figura de Adán, que supone precisamente el punto de unión entre la vieja y la nueva ley; luego, del 46 al 64, otra serie de autos sobre asuntos del Nuevo Testamento (entrada de Cristo en Jerusalén, prisión de San Pedro, circuncisión de Nuestro Señor, huida a Egipto, Resurrección, etc.); a continuación, aparte de dos excepcionales coloquios a lo divino (el de Fenisa y el de Fide Ypsa, números 65 y 66), una larga serie de farsas sacramentales que van de la 68 a la 92 (de Las cortes de la Iglesia, de Los sembradores, de La fuente de Sant Juan, de Peralforja, de La esposa de los Cantares, de La entrada del vino, del Desafio del hombre, de Las bodas de España, etc.), para cerrarse todo con un bloque final de cuatro autos de asunto diverso (del Descendimiento de la Cruz, de la Redención del género humano, de la Resurrección y de la Paciencia de Job), quizá anadidos por la misma pluma cuando, sin embargo, ya se había cerrado el plan de la recopilación.

Caracterizado, pues, el Códice de autos viejos como repertorio de representantes, quedaria por determinar ahora, si fuera posible, la compañía o el «autor» teatral con quien pudiera estar relacionado. Como hemos tratado de mostrar en otro lugar cuyas conclusiones resumimos aquí ${ }^{47}$, de entre los comediantes conocidos y más activos de la época (Jerónimo Velázquez, Nicolás de los Ríos, Gaspar de Porres, etc.), es Alonso de Cisneros el que más posibilidades tiene de estar vinculado a

sacrificio de Abraham (fols. 9-13v), Auto del destierro de Agar (14-16v), Auto de quando Abraham se fue a tierra de Canaán (17-20v), Aucto de quando Jacob fue huyendo a las tierras de Arán (21-24v), Auto de los desposorios de Ysac (25-30v), Coplas en loor del bienaventurado S. Francisco (31r), Coplas en loor del glorioso San Juan (31v). Coplas en lohor del glorioso S. Ambrosio (32-32v), Aucto de los desposorios de Isac (33-37), Farsa del Sacramento del Amor divino (37v-41v), Loa para qualquier autto (42r), A un prelado o otro señor (42r), A un pueblo (42-42v), Auto del robo de Digna (43-46v), Farsa sacramental de la residencia del hombre (47.50v).

${ }^{47}$ M. A. Pérez Priego, «El Códice de autos viejos y el representante Alonso de Cisneros», en Homenaje a Alonso Zamora Vicente, Madrid, Castalia, en prensa. 
una empresa semejante a la del Códice. Cisneros, cuya actividad dramática se desarrolla principalmente entre 1567 y 1595 , fue, en efecto, uno de los más prestigiosos y celebrados cómicos de entonces que, además, estuvo muy relacionado con Madrid y sus fiestas teatrales. Por la documentación conservada sabemos que aquí representó los autos del Corpus de los años 1578, 1580, 1582 (en 1581 no hubo representaciones por la muerte de Ana de Austria), 1590, 1591, 1593 y 1595: esto es, fechas muy próximas o poco posteriores a la compilación del Códice (algunos de cuyos títulos también consta que representó: el Hijo pródigo, el Sacrificio de Abraham, los Desposorios de Isaac o el auto de Tobias). Además Cisneros era el representante que en 1578 (como veíamos más arriba, la única fecha consignada en el Códice y en la que se autorizaba la representación del Auto de la Resurrección) tenía a su cargo las representaciones de la villa madrileña, en virtud de acuerdo firmado el $\mathbf{4}$ de marzo de ese año, por el que

*Alonso de Cisneros se concertó con esta villa que hará la fiesta del Santísimo Sacramento deste año de setenta y ocho, y hará tres autos quales esta villa señalare y escogiere de los que se le pidieren, con dos entremeses en cada auto, adereçados con los adereços que convengan (...) cada uno de los tres autos a contento desta villa de Madrid y del comisario qu'es della, y se le han de pagar por ello trescientos ducados y más veynte cinco ducados para ayudarle de llevar y traer los carros (...)"

Y lo que es aún más revelador: el 23 de mayo de ese mismo año, por un acuerdo sobre las «Fiestas del Corpus para adelante», el ayuntamiento madrileño encarga a dos comisarios, Pedro de Pereda y Francisco de Herrera, que contraten a Alonso de Cisneros como mantenedor asiduo de las representaciones de la fiesta del Corpus:

«traten con Cisneros representante para que se obliguen para que todos los días que viviere e pudiere tenga a su cargo la representación e fiesta del Corpus Christi desta villa» ${ }^{49}$.

En esas circunstancias, no sorprendería mucho que un avisado y ambicioso autor, como sin duda era Cisneros, se hubiera provisto de un

4* Archivo Municipal de Madrid, Libros de Acuerdos, vol. XXI, fol. 277; un extracto del documento fue publicado por C. Pérez Pastor, Nuevos datos..., cit., p. 11.

49 Archivo Municipal de Madrid, Libros de Acuerdos, vol. XXI, fol. 293v; hizo ya mención de este documento, aunque no transcribe el texto, N. D. Shergold, A History... cit., p. 418. 
copioso repertorio de piezas teatrales, como era el Códice de autos viejos, para ofrecerlo a la villa madrileña y en el que cómodamente se pudieran «señalar» y «elegir» los autos que se le pidieren. La villa, por su parte, a los pocos años de convertirse en corte, anhelaría aventajar a todas las demás ciudades en la celebración de las fiestas del Corpus contando para ello con un prestigioso representante fijo, al igual que, por ejemplo, años atrás había hecho Valladolid con Lope de Rueda. Ocurriría, sin embargo, que a pesar de todo Cisneros no llegaría a afincarse de cómico oficial en Madrid, y ni siquiera intervino ya al año siguiente en los autos del Corpus, que fueron representados por Mateo de Salcedo, aunque sí volvería a hacerlo, como quedó dicho, en 1580 y otros años después. La vertiginosa aceleración de la vida de las compañías teatrales y su continuo ir y venir de un lugar a otro, así como su misma proliferación y rivalidad, aparte la irrupción de los dramaturgos de fama con quienes en seguida aquéllas se sentirán obligadas, serían factores que detuvieran y sobrepasaran muy pronto la empresa comprometida por Cisneros.

\section{UN TEATRO SACRAMENTAL Y DOGMÁTICO}

A pesar de que, como dijimos, nuestra colección debe recoger sólo una parte de los «autos viejos» producidos en la época, el Códice es en su singularidad la muestra más representativa del teatro religioso que en los decenios posteriores a 1550 ejecutaban las compañías de actores y promocionaban los cabildos y ayuntamientos. Se trata, pues, de un teatro en gran medida oficial e institucionalizado, en cuanto promovido y controlado juntamente por la autoridad civil y la autoridad eclesiástica. Teatro que se produce fundamentalmente en torno a la fiesta del Corpus Christi, que es la que en esos momentos concentra y polariza el espectáculo dramático-religioso de la comunidad. Es por ello que, aunque en el Códice se incluyan también piezas que celebran otras festividades sagradas (Resurrección, Asunción, fiestas de santos) y otras muchas que no aluden expresamente al Sacramento, todas eran representadas ordinariamente en la fiesta del Corpus. De ese modo, y a pesar de su diversidad argumental, las distintas obras (autos del Antiguo Testamento, autos del Nuevo Testamento, farsas sacramentales, etc.) ${ }^{50}$ vienen a integrarse

so Sobre las distintas clasificaciones que se han hecho de las obras contenidas en el Códice, véase Léo Rouanet, ed. cit., I, pp. X-XI; Luigi Sorrento, «I Trionfi de Petrarca a lo divino e l'allegoria religiosa negli autos*, en Estudios eruditos in memoriam A. Bonilla y San Martin, II, Madrid, 1930, pp. 397-435; A. Valbuena Prat, Literatura dramática española, Barcelona, 1930; B. W. Wardropper, Introducción..., cit., pp. 219-28. 
en un todo dramático, en un gran drama único que recorre la historia de la salvación desde la creación y caída del hombre hasta su redención por la encarnación de Cristo y el misterio de la Eucaristía.

En ese todo teológico y dramático, los autos inspirados en el Antiguo Testamento valen como anuncio y preparación de la redención, en tanto que los del Nuevo, vidas de santos y leyendas piadosas recogen momentos puntuales de aquella historia de la salvación. Con todo, serán las varias piezas sobre la figura de Adán, que, como ya supo ver Luigi Sorrento ${ }^{51}$, constituyen una categoría independiente y original en el Códice, las que concentren mucho más eficazmente aquella idea dramática, en cuanto que Adán supone el punto de unión entre la vieja y la nueva ley y en él se encierra todo el proceso de la redención del género humano («el mundo está en mí cifrado», afirmará de sí mismo en el Auto de los triunfos de Petrarca, v. 115). No sorprende, pues, que en esas obras se ponga ya en marcha el procedimiento alegórico que transforma a Adán en el personaje del Hombre, que será redimido por Cristo en el Sacramento. Con ello, el auto ha sabido extraer del viejo drama de Adán de la tradición medieval ${ }^{52}$ una nueva y eficaz fórmula sacramental -ya patente en piezas como la Farsa del Sacramento de Adán-, acorde con las exigencias doctrinales que presiden el drama religioso quinientista.

Esa fórmula alegórica aparecerá ya plena y originalmente desarrollada en las llamadas «farsas sacramentales», las cuales suponen no sólo un teatro para el Corpus sino un auténtico teatro eucarístico ${ }^{53}$ cuyo asunto único es el misterio del Sacramento y cuya acción representada va directamente encaminada a descifrarlo e ilustrarlo. En unos casos (Farsa sacramental de la Bodas de España, F. sacramental de la moneda, $F$. del Sacramento llamada premática del Pan, etc.), se tratará de argumentos alegóricos con referentes en la propia realidad contemporánea o en sucesos de la vida diaria ${ }^{54}$; en otros, como es más frecuente, la alegoría estará inspirada en asuntos de «invinçión santa y divina», como los que tratan, por ejemplo, la $F$. del Sacramento llamada la Esposa de los Cantares o la $F$. del Sacramento del Amor divino. La primera desarrolla a lo divino el tema de la «adúltera perdonada», basándose en la tradición del Cantar de los Cantares y con el añadido de algún motivo celestinesco ${ }^{55}$.

51 Art. cit., pp. 403 y 409-14.

52 Sobre el origen del drama de Adán en los responsorios de Sexagésima, que suponen precisamente una preparación para la Pasión y Resurrección, vid. O. B. Hardison, Christian Rite and Christian Drama in the Middle Ages, Baltimore, 1965.

53 Vid. B.W. Wardropper, *The search for a dramatic formula for the auto sacramentals, PMLA (1950), pp. 1196-1205.

$\$ 4$ Vid. Jean-Louis Flecniakoska, ob. cit., p. 415.

s5 Véase ahora Louise Fothergill-Payne, «La cambiante faz de La Celestina (Cinco adaptaciones de fines del siglo XVI)», Celestinesca, VIII (1984), pp. 29-41. 
el Alma, seducida por el enemigo, se arrepiente del engaño y es perdonada por el Esposo, Cristo, que además le ofrece el Sacramento como salvación y símbolo de la reconciliación. La segunda pone en escena la metáfora continuada del "grano de trigo» que, desde la siembra hasta su elaboración en pan, según van describiendo los sucesivos personajes que comparecen en escena (Labrador, Sembrador, Segador, Trillador, Panadera, Hornera), simboliza los distintos episodios de la vida y muerte de Cristo que se da al pecador en el pan eucarístico. En ambos casos estamos ante alegorías que proyectan lo puramente teológico a un plano más lírico y dramático, rico en motivos populares y pintorescos. Ello explica, sin duda, la larga trayectoria de ambas alegorías en la literatura sacramental y la especial predilección que por ellas sintieron autores como Valdivielso, Tirso y, sobre todo, Lope de Vega ${ }^{56}$.

En el plano conceptual, las obras del Códice contienen, más que una mera exposición, una proclamación estricta de la doctrina católica más ortodoxa. Aparte la lección moral y parenética que encierran los autos inspirados en la Biblia, en la leyenda dorada o en diferentes tradiciones piadosas, en general todas las piezas convergen en un punto teológico único: la exaltación del sacramento de la Eucaristía. El Sacramento pasa a ser así el dogma fundamental de la doctrina, ya que en él, como se afirma en un pasaje de la Farsa del Entendimiento niño, que destacó oportunamente Wardropper ${ }^{57}$, se cifran y hallan explicación todos los demás dogmas:

\author{
En la Criaçión ya atino, \\ y la Trinidad dejemos, \\ de la Encarnaçión no tratemos: \\ deste misterio divino \\ del Sacramento hablemos, \\ que si aquesto entenderé, \\ esotro podré creello.
}

(vv. 350-56)

La exposición de la doctrina eucarística, por lo demás, se ajusta fielmente a los decretos de las sesiones tridentinas, por lo que reiteradamente las farsas insisten en unos mismos puntos teológicos, como el de la

\footnotetext{
56 Sobre la tradición de esos temas, véase Franke Gewecke, Tematischen Untersuchungen zu dem vor-Calderonianischen 'Auto Sacramental', Ginebra, 1974, pp. 162 y ss.; y Louise Fothergill-Payne, La alegoria en los autos y farsas anteriores a Calderón, Londres, 1977, pp. 102-17.

${ }^{7}$ Introducción..., cit., pp. 113-14.
} 
institución del Sacramento, la presencia real, la transubstanciación, o la proclamación de la fe como única vía de acceso al misterio:

Fe

Pues agora has de ir vendado

los ojos, que ansí conviene, porque Aquél que fin no tiene has de serville atapado.

Racional ¡Oh, qué gran dolor me viene!

¡Cómo! ¿Y ansí tengo de ir?

Ley Ansina me has de seguir, pues por haberte seguido se han muchos hombres perdido.

(F. del Sacramento de Adán, vv. 321-29),

lo que lleva asimismo a rechazar, en línea con el más severo escolasticismo, los peligrosos desvíos del apetito racional que se atreve a escrutar los propios designios divinos:

El que entendimiento tiene

jamás le deje meter

en cosas que no conviene,

porque se podria perder.

(F. del Entendimiento niño, vv. 291-94).

Desde esos supuestos no será raro que igualmente aparezcan en el $C 6$ dice ocasionales ataques a la herejía y se viertan duras acusaciones contra Lutero o contra la vieja ley judaica ${ }^{58}$.

Respecto de su composición, tal vez sea aquel mentado carácter institucional el que confiere a las piezas del Códice su notoria uniformidad artística. Efectivamente, dejando aparte la recurrencia de temas, mo-

58 Vid. Julio Rodríguez-Puertolas, «La transposición de la realidad en el Códice de Autos Viejos*, en De la Edad Media a la edad conflictiva, Madrid, 1972, pp. 280-302. En aunque lógicamente, más que de una refutación expresa de su doctrina, se trata siempre de una condena en términos genéricos (véase, p. e., $F$. del sacramento / vino aquel Lutero no dalles pan y palo / estoy en tribulaçion, / y por aqueste resión contra el género hu. malo / a negar la confisión*, vv. 46-51, 316-21, O Auto de Luterano (como en la $F$. del mano, vv. 81-90), o de una burla ridícula 272 y ss., o en la $F$. sacramental de la moneda, sacramento llam
vv. 340 y ss.). 
tivos, personajes e incluso series de versos idénticos que aparecen en obras distintas 59 , todas son, en el orden compositivo, piezas breves en un acto y de proporciones semejantes: alrededor de los quinientos versos, casi siempre en quintillas (sólo excepcionalmente habrá alguna en prosa o en un metro diferente) ${ }^{60}$. Normalmente la obra responde a una composición tripartita constituida por una «loa» o "argumento», el cuerpo dramático de la pieza y una parte final cantada, aunque tanto ésta como la parte inicial pueden faltar en alguna ocasión.

La «loa» o «argumento», que a veces está escrito en prosa, incluye, aparte de otros circunstanciales tópicos del exordio y de la presentación de la obra (encarecimiento de ésta, tópico de lo indecible, etc.), el saludo reverencial al auditorio, la obligada demanda de silencio y atención y, con frecuencia, un adelanto del argumento que se va a representar. La parte final cantada viene constituida en ocasiones por un himno litúrgico (De profundis, Te Deum, etc.), pero normalmente se trata de un "villancico» o "copla» que suele alojar un resumen lírico y condensado del tema, con abundancia de motivos conceptuosos en las farsas sacramentales.

El cuerpo dramático, por su parte, desarrolla una acción de ordinario inspirada en una fábula dada, que procede la mayoría de las veces de la Biblia o de la hagiografía y excepcionalmente de los apócrifos o de otras leyendas piadosas ${ }^{6}$. Sólo las farsas sacramentales, como quedó apuntado, ofrecen una mayor y más libre invención en sus argumentos alegó-

59 Compárense, por ejemplo, Auto del Magná, vv. 1-20, y Farsa del Sacramento de la fuente de Sant Juan, vv. 46-65; Farsa sacramental llamada desafio del hombre, vv. 590-94, y Farsa del Sacramento de la entrada del vino, vv. 334-38, etc.

60 «La grande unité du Códice de Autos Viejos, par contre, est constituée par la versification: sur 96 pieces, 6 seulement [el auto de San Francisco, el de la Culpa y Captividad, el de Las donas que envió Adán a Nuestra Señora, la Farsa del Sacramento, la del Pueblo gentil y la de Moselinal contiennent des vers de pie quebrado, toutes les autres sont en quintillas, sauf la Paciencia de Job [en strophes ABBAB (hendecasyllabes)]» (J.-L. Flecniakoska, ob. cil., pp. 275-76). En prosa están compuestos el Auto del robo de Digna (parcialmente), el Entremés de las esteras, el Auto de los desposorios de Moysén (excepto el «argumento* y la *octava* final) y el Auto de Naval y Abigail.

${ }_{61}$ El Aucto de los desposorios de Joseph se deriva de la *Historia de Asenet», leyenda de origen musulmán o judio, que recoge por ejemplo Vicente de Beauvais en su Speculum historiale, XI, 118 (vid. Leo Rouanet, ob. cit., IV, pp. 179-80). Como indić Menéndez Pidal, kel Auto de los desposorios de Moisés, por derivarse de la narración de Josefo y de Pedro Coméstor, aparece emparentado con la General Estoria de Don Alfonso el Sabio, que acogió la misma anécdota en el cap. LIII de su lib. XI, y el Auto del Emperador Juveniano, de asunto comprendido en la Gesta romanorum, está emparentado con la más vieja adición del Conde Lucanor y con antiguas leyendas moriscas» (reseña a la ed. de Rouanet, en $R A B M, V, 1901$, p. 260). El Auto de la destruición de Jerusalén es una adaptación dramática derivada de la leyenda de la Vindicta Salvatoris recogida por los apócrifos y difundida en la Edad Media a través de numerosas versiones (vid. María Rosa Lida de Malkiel, Jerusalén. El tema literario de su cerco y destrucción por los romanos, Buenos Aires, 1972). 
ricos. En todos aquellos casos, el autor se limita a seguir puntualmente el discurso narrativo de la fuente, introduciendo sólo algunas modificaciones por exigencias de la nueva forma representacional y dialogada que ahora adopta. Lo habitual, en este sentido, es la amplificación poética o histórica de la fuente mediante el desarrollo de extensos monólogos o de nuevos núcleos escénicos que allí sólo estaban enunciados. A veces lo que se produce es una simple alteración en el orden de los sucesos o un desdoblamiento de personajes. En otros casos, sobre todo cuando se trata de una fuente más novelesca y extensa, es constante la abreviación de situaciones y personajes, como puede advertirse en el Auto de la destruición de Jerusalén ${ }^{62}$. Muy frecuente es también la amplificación por medio de escenas alegóricas que cierran la obra de forma solemne y apoteósica y que suelen encerrar una moralización o una prefiguración simbólica de lo representado (como en el Auto de los desposorios de Isaac, donde aparecen Alegoría, Moralidad y Letra explicando el sentido de la obra), o por medio de escenas pastoriles, a manera de intermedios cómicos, que a veces interrumpen la acción principal del auto (el coloquio rústico entre Zamarro y Usal en el Auto de Agar). De todos modos, tanto en estas escenas pastoriles como en las loas - que han venido a sustituir al viejo introito pastoril-, se advierte, en relación con los intermedios e introitos del teatro de la primera mitad del siglo, un notable aligeramiento de los elementos jocosos y hasta procaces que allí tantas veces aparecían mezclados con lo sagrado y que este teatro dogmático de la segunda mitad ya no parece dispuesto a soportar.

$62 \mathrm{El}$ auto es una adaptación de la pseudo-novela caballeresca la Historia del noble Vespasiano, repetidamente editada desde 1490 (entre las obras de aquel género la editó A. Bonilla en la segunda parte de sus Libros de caballerias, NBAE, vol. 11, pp. 379-401), aunque seguramente, como propone David Hook, a través de la version quinientista $\mathrm{La}$

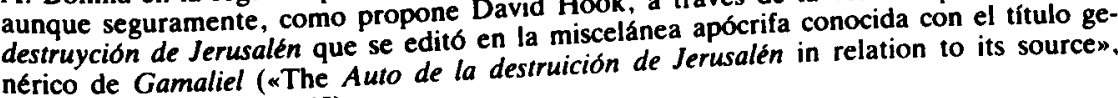
$B H S$, LI, 1974, pp. 335-45). 